\title{
Avaliação ultra-estrutural de fibras tendíneas de eqüinos acometidos por tendinite
}

\section{Ultra-structural evaluation of tendon fibers in equine suffering from tendinitis}

\author{
Ana Liz Garcia Alves, ${ }^{\star}$ Flavia Marinho Schubert, ** Armen Thomassian, ${ }^{*}$ Carlos Alberto Hussni, \\ José Luiz de Mello Nicoletti, ${ }^{\star}$ Adalberto José Crocci" ${ }^{\star \star \star}$
}

\begin{abstract}
Resumo
O presente trabalho objetivou estudar os aspectos ultra-estruturais da tendinite eqüina em animais que vieram a óbito durante o segundo semestre de 1999 e primeiro de 2000, no Hospital Veterinário da FMVZ - Unesp - Botucatu. Estes animais foram avaliados clínica e ultra-sonograficamente antes ou logo após suas mortes para confirmação da presença de tendinite. As amostras tendíneas coletadas foram submetidas imediatamente aos procedimentos de rotina para análise sob a microscopia eletrônica. Esta análise revelou-se eficaz como método de avaliação estrutural dos tendões, eficiente na mensuração transversal das fibrilas tendíneas e suficiente para a diferenciação entre normal e alterado.
\end{abstract}

Palavras-chave: eqüino; tendão; microscopia eletrônica.

\begin{abstract}
The aim of this study was to investigate the ultra-structural aspects of the equine tendinitis in ten animals that died during the second semester of 1999 and the first of 2000, at the Veterinary Hospital of FMVZ - UNESP - Botucatu and at São Paulo's Jockey Club. These animals were evaluated clinically and ultra-sonographically before or right after their deaths to confirm the existence of tendinitis. The tendon samples collected were submitted immediately to the routine procedures for light and electron microscopy analysis.
\end{abstract}

Keywords: equine; tendon; electron microscopy; tendinitis.

\section{Introdução}

Os tendões e ligamentos situados na região distal dos membros dos eqüinos têm notória importância anatômica, funcional, clínica e patológica, uma vez que se tornaram estruturas extremamente resistentes que sustentam cargas e tensões elevadas (Denoix, 1994). Esta seleção, para aumentar a resistência e velocidade, deve ter ocorrido inicialmente objetivando a própria sobrevivência do animal e, posteriormente, com sua domesticação, o transporte e lazer.

As estruturas tendíneas são freqüentemente acometidas por lesões, tais como tendinites e rompimento da estrutura tendinea (Alves, 1998; Genovese, 1990; Rantanen, 1998; Williams, 1989). Estas lesões diminuem a função do animal, fazendo com que muitas vezes não retornem à sua performance inicial.

As lesões nos tendões flexores dos eqüinos ainda representam um dos maiores desafios quanto a monitoração clínica e prognóstico. Estas ocorrem, em diversas estruturas flexoras colágenas, tanto nos membros anteriores como nos posteri- ores; com predileção, em cavalos de corrida, para o tendão do músculo flexor digital superficial. A diferença na incidência do local lesado pode ser explicada pela análise de distribuição de cargas entre as estruturas flexoras nos diferentes tipos de locomoção do animal em associação com uma demanda locomotora específica (Fackelman, 1973). A conformação, idade, nível de treinamento e tipo de ferradura também estão implicados na etiopatogenia das lesões. No entanto, os mecanismos específicos e suas inter-relações envolvidos na gênese das lesões não são bem conhecidos.

O conhecimento ultra-estrutural das características das fibras colágenas de um tendão em recuperação, submetido a processo inflamatório, é escasso na literatura mundial.

$O$ presente trabalho tem por objetivo analisar o tamanho e configuração de fibrilas tendíneas de eqüinos acometidos por tendinite sob a microscopia eletrônica. A importância desta análise está no melhor conhecimento desta enfermidade inflamatória sob o aspecto patológico, proporcionando-nos novas opções terapêuticas para a recuperação da estrutura tendínea.

\footnotetext{
* Docentes do Depto. de Cirurgia e Anestesiologia Veterinária pela FMVZ-UNESP, Botucatu, SP.

** Aluna de iniciação científica/ Bolsista Pibiq/CNPq.

*** Docente do Depto. de Bioestatística do Instituto de Biociência pela FMVZ-UNESP, Botucatu, SP.
} 


\section{Material e métodos}

Foram coletadas amostras do tendão do músculo flexor digital superficial de vinte eqüinos que vieram a óbito na FMVZ durante o segundo semestre de 1999 e primeiro semestre de 2000 , em razão de enfermidades não relacionadas com o aparelho locomotor. Destes, dez apresentavam sinais clinicos de tendinite (grupo tendinite) e dez exibiam normalidade no aparelho locomotor (grupo controle).

Os animais destinados ao sacrifício foram previamente avaliados por exames clínico e ultra-sonográfico.

Com os animais em posição quadrupedal, após tricotomia da região metacarpiana, face palmar, bilateral buscaram-se lesões através do exame clínico local e ultra-sonográfico da região metacarpiana. $O$ equipamento utilizado foi o ultra-som linear com transdutor de 7,5 Mhz.' As imagens obtidas foram congeladas e impressas para posterior análise.

Após o óbito do animal, procedeu-se à necrópsia para a retirada dos fragmentos.

Realizou-se a excisão de fragmentos de $1 \mathrm{~mm}^{2}$ envolvendo o local da lesão no grupo tendinite, e no grupo controle a excisão envolveu a região central do terço médio do metacarpiano, com auxílio de bisturi e pinça.

Os fragmentos retirados foram imersos em solução de glutaraldeido, para, posteriormente, serem submetidos ao processamento de rotina e análise sob microscópio eletrônico no Laboratório de Patologia da Faculdade de Medicina de Unesp - Botucatu, SP.

Os fragmentos retirados foram fixados da maneira convencional para microscopia eletrônica e embebidos em rezina epoxy. Foram feitos cortes de 90 a $130 \mathrm{~nm}$ de espessura usando-se uma faca de diamante e estes foram colocados em uma malha quadriculada de cobre. Os cortes foram corados com acetato de urânio seguido de citrato de chumbo modificado.

Utilizando-se um paquímetro de leitura digital, foram realizadas as medidas dos diâmetros de fibrilas, escolhidas ao acaso, contidas nos quadrados do retículo utilizado.

Para análise dos resultados foram utilizados testes paramétricos, levando-se em consideração a natureza das distribuições dos valores estudados e a variabilidade das medidas efetuadas. O teste utilizado foi o teste $t$ de Student simples, não pareado para amostras independentes (Zar, 1996).

\section{Resultados e discussão}

Os resultados obtidos ao exame ultra-sonográfico mostraram que, dos dez membros com características clínicas ou ultra-sonográficas de tendinite, cinco apresentaram lesão de evolução aguda, e cinco com evolução crônica.

As lesões tendineas foram identificadas por imagens hiperecóicas intercaladas com imagens hipo ou anecóicas dispostas de forma difusa na maioria dos membros, o que gerou certo grau de dificuldade na delimitação destas, levan-

\footnotetext{
' Pie Medical 480.
}

do-nos a recorrer ao mapeamento das regiões sem paralelismo das fibras. Esta dificuldade do diagnóstico preciso das áreas de lesão crônicas é compatível com relatos de Genovese et al. (1990); Denoix (1994) e Rantanen et al. (1999) de que as lesões agudas são de mais fácil diagnóstico. A característica ultra-sonográfica de maior relevância foi a ausência de paralelismo das fibras colágenas em sete dos dez animais selecionados. Dos três restantes, dois apresentaram paralelismo parcial e um, paralelismo total das fibras.

Ao exame clínico do tendão, confirmamos a sanidade dos membros sadios no grupo controle e as áreas de lesões no grupo tendinite, o que corrobora com os relatos experimentais de Williams (1989) e Alves (1998) que referem a identificação nítida das lesões, através de inspeção macroscópica, após sacrifício dos animais. Em quatro membros observouse aderência próximo às áreas das lesões, localizada entre os tendões dos músculos flexores digitais superficial e profundo em três animais e entre o tendão do músculo flexor digital superficial e paratendão em um membro.

A avaliação ultra-estrutural do material coletado do grupo controle mostrou semelhança das características morfológicas. Foi observada uma pequena proporção de fibroblastos em relação aos fibrócitos. Os fibroblastos foram caracterizados como células com um retículo endoplasmático rugoso abundante, com material granular presente na cisterna dilatada, aparelho de Golgi desenvolvido, núcleo grande e cromatina fina. Já as células caracterizadas como fibrócitos apresentaram menor tamanho celular em relação aos fibroblastos, menor número de prolongamentos e deficiência em retículo endoplasmático rugoso. Estes achados estão de acordo com o descrito por Junqueira e Carneiro (1999), que relatam também a transformação de fibrócitos em fibroblastos caso haja um estímulo adequado. O espaço extracelular adjacente à membrana celular mostrou conter proteoglicanos e colágenos. Os proteoglicanos apareceram como uma massa amorfa. As fibras colágenas foram identificadas como filamentos lineares próximas umas às outras.

Já nos membros com caracteristicas de processo inflamatório tendíneo, observou-se uma proporção maior de fibroblastos em relação a fibrócitos na maioria das amostras. Este relato está de acordo com Silver et al. (1983) e Goodship et al. (1994), pois, segundo estes autores, antes de qualquer fibrila visível aparecer no processo de reparação, o retículo. endoplasmático do fibroblasto forma o pró-colágeno que é o precursor da molécula de colágeno, já no meio extracelular. Isto significa que um processo de reparação deve conter uma grande quantidade de fibroblastos ativos com suas organelas, em especial o retículo endoplasmático rugoso aumentado em quantidade e dimensão.

Damsch et al. (1992) observaram, ultra-estruturalmente, em eqüinos com tendinite crônica degeneração de fibrilas colágenas, edema do feixe das fibrilas, reabsorção de fibrilas por macrófagos e locais com calcificação distrófica. Em nosso experimento verificamos algumas fibrilas fragmentadas e degeneradas dispostas de maneira desorganizada, indicando um padrão randômico das fibrilas colágenas nos feixes tendíneos, sendo provavelmente o responsável pela perda da elasticidade e recidiva do processo inflamatório. O que diferiu dos estudos de Damsch et al. (1992) é a não observação da presença de calcificação distrófica nas amostras coletadas. 
Para se avaliar os diâmetros das fibrilas foram feitos cortes transversais que são mostrados nas fotomicrografias (Figuras 1 e 2), onde pôde ser observado o aspecto circular das fibrilas.

No material do grupo controle analisado as características das fibrilas colágenas foram morfologicamente semelhantes. Os diâmetros destas fibrilas colágenas nas diferentes amostras utilizadas como controle estão apresentados na Tabela 1 e na Figura 1. Estas mensurações mostraram que houve uma variação de $82 \mathrm{~nm}$ a $127 \mathrm{~nm}$, com média de 103,4 $\mathrm{nm}$. Medidas estas, aproximadas aos valores citados por Goodship e Birch (1996) que referiram como padrão para estruturas tendíneas de eqüinos adultos, fibrilas de 120 a $200 \mathrm{~nm}$. As diferenças entre o nosso estudo e estes relatos, onde a média dos diâmetros das fibrilas foi menor, podem ser justificadas pela menor idade dos animais do experimento, diferentes estágios de atividades físicas ou até em função destes autores terem apresentado uma média de estruturas tendíneas incluindo o tendão do músculo flexor digital superficial e o tendão do músculo gastrocnêmio. Em nosso experimento, somente avaliamos o tendão do músculo flexor digital superficial. O modo de selecionar as fibrilas a serem medidas é outro fator importante que pode, talvez, influenciar nos resultados.

Os diâmetros das fibrilas do grupo tendinite estão apresentados na Tabela 1 e Figura 2, os quais sofreram uma variação de $38 \mathrm{~nm}$ a $103 \mathrm{~nm}$ com média de $61,8 \mathrm{~nm}$, sendo que em uma das amostras o diâmetro das fibrilas foi semelhante a um dos diâmetros controle. Os diâmetros das fibrilas do grupo tendinite estão de acordo com o encontrado por Damsch et al. (1992), que também relataram a presença de fibrilas de menor diâmetro em tendões acometidos por tendinite analisados por microscopia eletrônica.

As diferenças entre o grupo controle e o grupo tendinite foram estatisticamente significativas.

No presente experimento as fibrilas de pequeno diâmetro do grupo tendinite foram consideradas fibrilas recém-formadas, o que é interpretado como expressão de uma síntese colágena amplificada. Ainda que não tenha sido determinado o tipo de colágeno, trata-se aqui, provavelmente, do colágeno tipo III, que é formado no início da reparação.

Acrescentado a uma multiplicação diversa de fibrilas finas do grupo tendinite, observamos uma fração pequena de fibras maduras com um diâmetro maior do que $86 \mathrm{~nm}$, o que, segundo Rydell (1970), relaciona com uma provável reabsorção destas fibrilas colágenas com maior diâmetro devido à elevada fagocitose dos macrófagos que estão presentes nos processos inflamatórios ativos da regeneração tendínea.

Quanto à desorganização do tecido lesado, os achados do grupo tendinite estão de acordo com a literatura consultada (Silver et al., 1983), que relata um padrão randômico das fibrilas colágenas nos feixes tendíneos, sendo o responsável pela perda de elasticidade e recidiva do processo.

A presença de fibroblastos com grande quantidade de retículo endoplasmático rugoso, bem como a grande concentração de material granular nas cisternas, indicam uma síntese colágena elevada, compatível com a presença de fibrilas finas recentemente formadas, representado na reação inflamatória.
Tabela 1: Diâmetro das fibrilas colágenas nos grupos de animais normais e acometidos por tendinite $(n=20)$

\begin{tabular}{lclc}
\multicolumn{2}{c}{ GRUPO CONTROLE } & \multicolumn{2}{c}{ GRUPO TENDINITE } \\
\hline ANIMAL & DIÂMETRO $(\mathrm{nm})$ & ANIMAL & DIÂMETRO $(\mathrm{nm})$ \\
1 & 127 & 11 & 53 \\
& 102 & 12 & 38 \\
3 & 96 & 13 & 65 \\
4 & 106 & 14 & 86 \\
5 & 98 & 15 & 42 \\
6 & 111 & 16 & 58 \\
7 & 126 & 17 & 103 \\
8 & 100 & 18 & 42 \\
9 & 86 & 19 & 58 \\
10 & 82 & 20 & 73 \\
MÉDIA & $103.4^{\circ}$ & MÉDIA & $61.8^{\circ}$ \\
DESVIO-PADRÃO & 14.871 & DESVIO-PADRÃO & 20.751 \\
\hline
\end{tabular}

${ }^{*}$ Houve diferença significativa entre os dois grupos de animais $(p<0,001)$

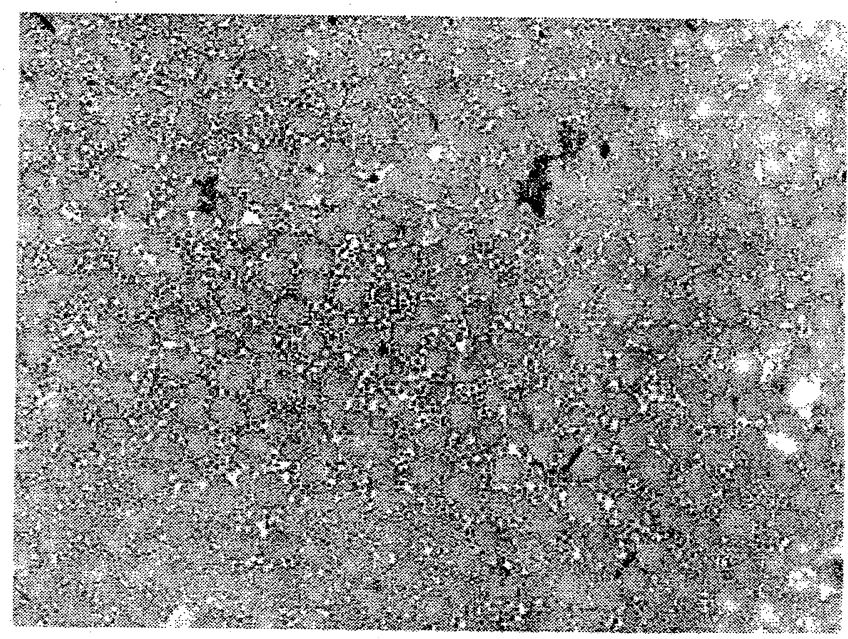

Figura 1: Fotomicrografia eletrônica de transmissão de corte transversal do Tendão do músculo flexor digital superficial do grupo controle. Notar o aspecto circular das fibrilas e maior uniformidade nos diâmetros. $30.000 \mathrm{X}$

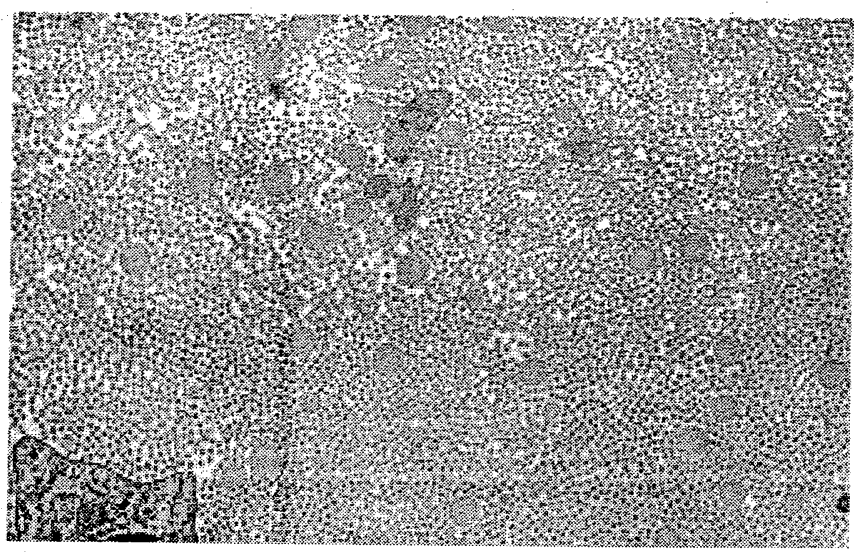

Figura 2: Fotomicrografia eletrônica de transmissão de corte transversal do tendão do músculo flexor digital superficial do grupo tendinite. Notar a grande variação nos diâmetros das fibrilas. $30.000 \mathrm{X}$. 


\section{Conclusões}

- A utilização da microscopia eletrônica demonstrou ser um parâmetro eficaz na avaliação da morfologia e constituição das estruturas tendíneas de eqüinos em membros sadios e acometidos por processo inflamatório.

\section{Referências}

ALVES, A. L. G.; BORGES, A. S.; AGUIAR, A. J. A.; RODRIGUES, C. A R.; MENDES, L. C. N. Influência do fumarato de beta-aminopropionitrila associado ao exercício sobre a cicatrização tendínea de eqüinos. CONGRESSO BRASILEIRO DO CBCAV, 3., 1998, Belo Horizonte. Anais...,1980. p. 132.

BARROS, S. P. Estudo morfométrico ultra-estrutural da matriz extracelular do ligamento periodontal do incisivo inferior de ratos, em diferentes regiões e zonas, nas condições de erupção impedida, desimpedida e retardada pela vimblastina. 1995. 48p. Tese (Doutorado) - Faculdade de Odontologia de Piracicaba, Universidade Estadual de Campinas.

BERTONE, A L. Equine tendinitis. J. Equine. Vet. Sci., v. 16, p. 16-17, 1996.

DALE, W.C.; BAER, E. Fibre-bucking in composite systems: A model for the ultrastructure of uncalcified collagen tissues. J. Mater. Sci., v. 9, p. 369-82, 1974

DAHLGREN, L. A.; ROSENBUSCH, R. F.; BOOTH, L. C. Development of an in vitro Model for the Study of the Response of Equine Tendon Fibroblasts to Injury and Medication. Vet. Comp. Orthop. v. 10, p. 6-11, 1997.

DAMSCH, S.;DROMMER, W.; SCHMIDT, W.; HERTSCH, B. Intratendinöse Injektion von hochmolekularem Natrium-hyaluronat bei Pferden mit chronische Tendinitis - Klinische, licht und elektronenmikroskopische Befunde. Pferdeheilkunde, v. 6, p. 333-343, 1992.

DENOIX, J. M. Diagnostic techniques for identification and documentation of tendon and ligament injuries. Vet. Clin. North Am. Equine Pract., v. 10, p. 365-407, 1994.

DROMMER, W., DAMSCH, S., WINKELMEYER, S. et al. Rasterelektronenmikroskopische Befunde an Strahlbein und tiefer Beugesehne bei der Podotrochlose des Pferdes. Deutsche Tierärztl. Wochensch., v. 6, p. 235-241, 1992.

DYSON, S. J. The use of ultrasonography for assessment of tendon damage. Equine Vet. Educ., v. 1, p. 42, 1989.

FACKELMAN, G. E. The nature of tendon damage and its repair. Equine. Vet. J., v. 5, p. 141-149, 1973.

GENOVESE, R. L.; RANTANEN, N.;W.; SIMPSON, B. S. et al. Clinical experience with quantitative analysis of superficial digital flexor tendon injuries in thoroughbred and standardbred racehorses. Vet. Clin. North Am. Equine Pract., v. 6, p. 129-145, 1990.

GENOVESE, R. L. Trearment of superficial digitl flexor tendinitis - An opinion. In: GENOVESE, R. L., RANTANEN, N. W. Equine diagnostic ultrasonographic. Baltimore: Williams \& Wilkins, 1998. p. 289-398.

GOODSHIP, A. E.; BIRCH, H. L. The Pathophysiology of the flexor tendons in the equine athlete. In: DUBAI INTERNATIONAL EQUINE SIMPOSIUM, 1996, Dubai. Proceedings..., 1996, p. 83-107.
- A técnica de mensuração do diâmetro das fibrilas tendíneas, em plano transversal, utilizada neste experimento, foi eficiente e de fácil execução.

- As características morfológicas ultra-estruturais encontradas neste experimento foram suficientes para diferenciar o tecido tendíneo íntegro do inflamado.

GOODSHIP, A .E.; BIRCH, H.L.; WILSON, A. M. The Pathophysiology and repair of tendon and ligament injury. Vet. Clin. North Am. Equine Pract, v. 10, p. 322-349, 1994.

HILL, W. G. Why aren't horses faster? Nature, v. 322, p. 678, 1988.

JUNQUEIRA, L. C.; CARNEIRO, J. Histologia Básica. Rio de Janeiro: Guanabara Koogan, 1999. p. 80-81.

KASTELIC, J.; GALESKI, A.; BAERE. The multicomposite structure of tendon. Connect Tissue Res., v. 6, p. 11-23, 1978.

NIMNI, M. E.; HARKNESS, R. D. Molecular structure and functions of collagen. Boca Raton: CRC, 1988.

PATTERSON-KANE, J. C.; FIRTH, E. C.; WILSON, A. M. et al. Companison of collagen fibril populations in the superficial digital flexor tendons of exercised and non-exercised thoroughbreds. Equine Vet. J., v. 27, p 185-189, 1995.

PATTERSON-KANE, J. C.; FIRTH, E. C.; PARRY, D. A. D. et al. Effects of training on collagen fibril populations in the suspensory ligament and deep digital flexor tendon of young Thoroughbreds. Am. J. Vet. Res., v. 59, p. $64-68,1998$

PARRY, D. A. D.; CRAIG, A. S. Growth and development of collagen fibrils in connective tissue. In: RUGGERI, A.; MOTTA, P. M. (Eds.) Ultrastructure of the connective tissue matrix. The Haghe, Martinus Nijhoff, 1984. p. 34-64.

ROBBINS, S. L.; COTRAN, R. S.; KUMAR, V. et al. Inflamation and repair. In: ROBBINS, S. L.; COTRAN, R. S.; KUMAR, V. et al. Pathologic basis of disease. Pennsylvania: W.B. Saunders Company, 1994. p. 51-92.

RANTANEN, N. W.; GENOVESE, R. L. The Superficial Digital Flexor Tendon. In: RANTANEN, N. W.; MCKINNON, A. O. Equine Diagnostic Ultrasonography. 1st ed. Baltimore: Williams \& Wilkins, 1998.

RYDELL, N. Decreased granulation tissue reaction after installment of hyaluronic acid. Acta. Orthop. Scand., v. 41, p. 307-311, 1970.

SHORE, R. C.; MOXHAM, B. J.; BERKOVITZ, B. K. B. A quantitative comparison of the ultrastructure of the periodontal ligaments of impeded and unimpeded rat incisors. Archs. Oral Biol., v. 27 p. 423-430, 1982. SILVER, I. A.; BROWN, P. N.; GOODSHIP, A. E. et al. A clinical and experimental study of tendon injury, healing and treatment in the horse: Equine Vet. J.suppl. 1, p. 5-22, 1983.

WATKINS, J. P. Tendon and ligament biology. In: AUER, J. A.; STICK, J. A. Equine Surgery. Pennsylvania: W. B. Saunders, 1999. p. 704-705.

WILLIAMS, P. L.; WARWICK, R.; DYSON, M. et al. The connective tissues. In: GRAY, H., WILLIAMS, P. L. Gray's Anatomy. Edinburgh: Churchill Livingstone, 1989. p. 58-70.

WILMINK, J.; WILSON, A. M.; GOODSHIP, A. E. Functional significance of the morphology and micromechanics of collagen fibres in relation to partial rupture of the superficial digital flexor tendon in racehorses. Res. Vet. Sci., v. 53, p. 354-359, 1992.

ZAR, J. H. Biostatistical analysis. Upper Saddle River: Prentice Hall, 1996. 